\title{
Development of a digitally-controlled single-axis earthquake shake frame for masonry walls testing
}

\author{
M. J. Guzman \& S. L. Lissel \\ Department of Civil Engineering, University of Calgary, Canada
}

\begin{abstract}
For the evaluation of masonry specimens' response under seismic forces, a 2actuator, single-axis shake frame was developed at the University of Calgary. The system works with hydraulic power and contains specialized hardware and software for management and control. These include MTS Multipurpose TestWare for the control of the Hydraulic System and National Instruments SCXI and LabVIEW for the data acquisition. Tests using the El Centro earthquake (1940) with just the shake frame mass, and with additional mass (two $200 \mathrm{~mm}$ concrete masonry walls $1 \mathrm{~m}$ long $\mathrm{x} 1.6 \mathrm{~m}$ high), indicated the satisfactory functionality of the shake frame. In addition, a comparison between the masonry walls' behaviour under earthquake loads and a finite element (SAP2000) model was carried out and is presented here.
\end{abstract}

Keywords: shake frame, shake table, masonry, seismic load simulation.

\section{Introduction}

Structures are designed and built to withstand a variety of load conditions keeping in mind safety and economics. In the case of earthquake loads, some structures are more vulnerable than others. Depending on which material the structures are made of, their response and resistance to seismic forces will vary. Masonry structures, for example, are able to resist earthquake loads as long as they are properly designed but, to achieve that, studies and experimentation must be done. Since masonry is not a homogeneous material, the dynamic behaviour of masonry structures is a complex matter. The interaction between masonry units, mortar, grout and the reinforcement create a significant number of variables that influence the response of masonry to dynamic loading; 
deformation, damage pattern or failure modes will also be affected by the vibrations induced in the structure by the earthquake.

Seismic Simulation Tables, also know as Shake Tables, are generally used for experimentation on the dynamic behaviour of any type of structure. Using single-axis or multiple-axis excitation, these machines are able to accurately reproduce, in a laboratory environment, the acceleration time history recorded during an earthquake. In the global market they can be purchased at a price of US $\$ 150,000$ to over US\$1,000,000, depending on the complexity of their design. Hence, the cost of these devices is of significant influence in the experimentation process. In consideration of these factors, for the dynamic testing of masonry building components, in this case walls and wall intersections, a low-cost testing apparatus was designed and built at the University of Calgary.

Three main stages were involved in the development and construction of the testing apparatus: a) design process; b) construction process; and c) testing functionality of the apparatus.

\section{Shake frame}

\subsection{Design and construction}

The Shake Frame is a Single Degree Of Freedom (SDOF) seismic simulation apparatus for dynamic testing of masonry building components, in this case walls and wall intersections. Based on a general design by Hagel et al. [1], the main body of the frame consists of four W360x162 steel I-sections, creating a frame of $2 \times 3 \mathrm{~m}$ between respective beam centerlines. The robustness of the beams was selected so they could handle the internal forces and bending with negligible deformations. Because the frame was going to be attached to two hydraulic actuators parallel to each other but $2 \mathrm{~m}$ apart, torsion could be expected if there was a difference in force between them or if, in a worse case scenario, one of them stops while the other is still working. Therefore, bracing was designed to withstand the torsion. HSS $89 \times 89 \times 9.5$ sections were selected for this purpose (Figure 1).

Steel plates at the ends of the beams and the braces allow the use of bolted connections, so the frame can be easily modified or dismantled. All the connections were designed following the specifications in the Canadian standard; the connections between the frame and the braces were designed for shear, and connections between the reaction frames and the floor were designed as slip critical connections.

One of the considerations for the design was that the apparatus should travel with as little friction as possible; therefore, a Ball Bearing and Rail System was used for these purposes. Eight $750 \mathrm{~mm}$ long Roller Rail pieces and sixteen Roller Runner Blocks (two on each rail) were selected as the support and guidance system for the Shake Frame. A combination of different sizes of plates, and the application of a self-levelling grout with a thickness of approximately $6 \mathrm{~mm}$ between the plates, were used to attached the frame to the strong floor and compensate for alignment and levelling issues of the guide rails, allowing nearly frictionless displacement of the frame (Figure 2). 


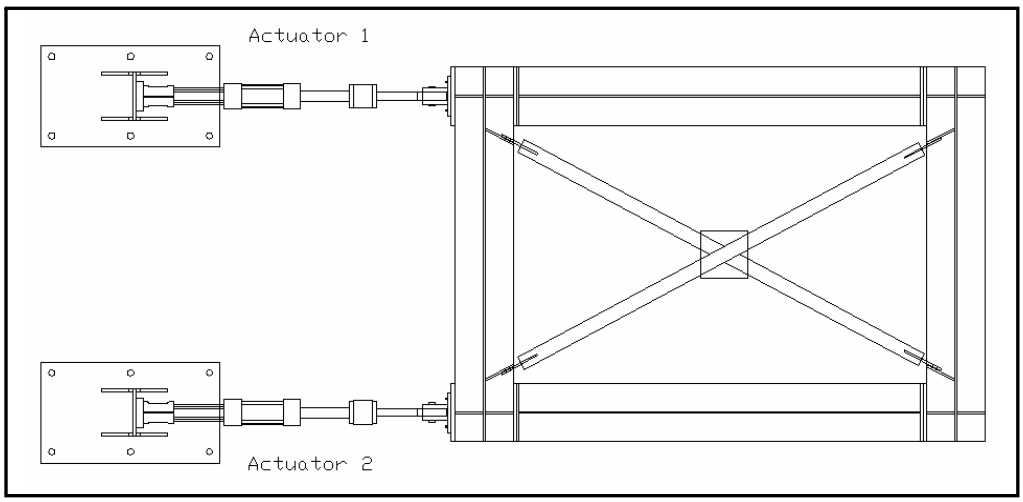

Figure 1: $\quad$ Shake frame plan view.

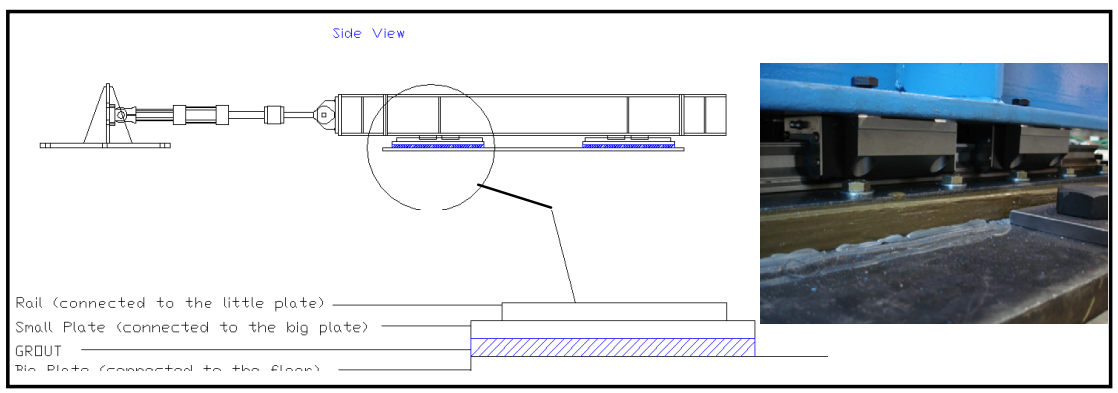

Figure 2: $\quad$ Plate arrangement for alignment compensation; and rail system.

The displacement, force capacity and speed of the Shake Frame are determined by the system's actuators, Ammanagi et al. [2]. These devices can provide a maximum load of $150 \mathrm{kN}$ each, a maximum displacement of $\pm 125 \mathrm{~mm}$, and they can operate without difficulty at the system design frequency of up to $4 \mathrm{~Hz}$.

\subsection{Hydraulic system}

To induce an earthquake signal, or a signal of any kind, to the shake frame, two hydraulic actuators were used. The actuators, the hydraulic power system that activates them, and the MTS Systems Corporation software that controls them will be referred to here as the hydraulic system. The hydraulic system produces and controls the movement of the shake frame. The hydraulic power system consists of a Hydraulic Power Unit (HPU), an accumulator, two Hydraulic Service Manifolds (HSMs), and two Actuators. The HPU produces the highpressure hydraulic fluid for the system operation. At high pressure, the hydraulic fluid is directed out of the HPU to the accumulator, which helps dampen 
pressure line fluctuations in the hydraulic system. From the accumulator, the hydraulic fluid goes to the HSMs. These are hydraulic pressure and flow regulation devices that provide an independent control of the hydraulic pressure applied to a test station. The manifolds allow each station to be turned on and off, and set to a low-pressure level, independently from each other and from the HPU. Finally, the hydraulic fluid reaches the actuators, which will put in motion the shake frame in force or displacement control. A FlexTest GT Test Controller is used to control the actuators and the HPU. This is a multi-channel, multistation control system that combines transducer signal conditioners, servovalve drivers, hydraulic pump and service manifold controls; and, a system control software, to manage servo devices in closed loop testing applications.

\section{Shake frame functionality}

\subsection{The quake}

The Imperial Valley 1940-05-19 04:37 earthquake had a magnitude of 6.95 on the Richter scale; the epicenter was located at 32.7601 latitude, -115.416 longitude, and at a depth of $8.8 \mathrm{~km}$.

Using the MTS MultiPurpose TestWare (MPT) software, the displacement time history data from the Imperial Valley 5/19/40-04:39, El Centro Array \#9, 180 (USGS Station 117), was programmed in the Hydraulic System. The maximum acceleration, velocity and displacement are $0.313 \mathrm{~g}, 298 \mathrm{~mm} / \mathrm{s}$ and $133.2 \mathrm{~mm}$ respectively. Due to limitations on the maximum displacement capacity of the actuators, the earthquake input signal was modified. The signal's maximum displacement was changed to $125 \mathrm{~mm}$ (Figure 3 ).

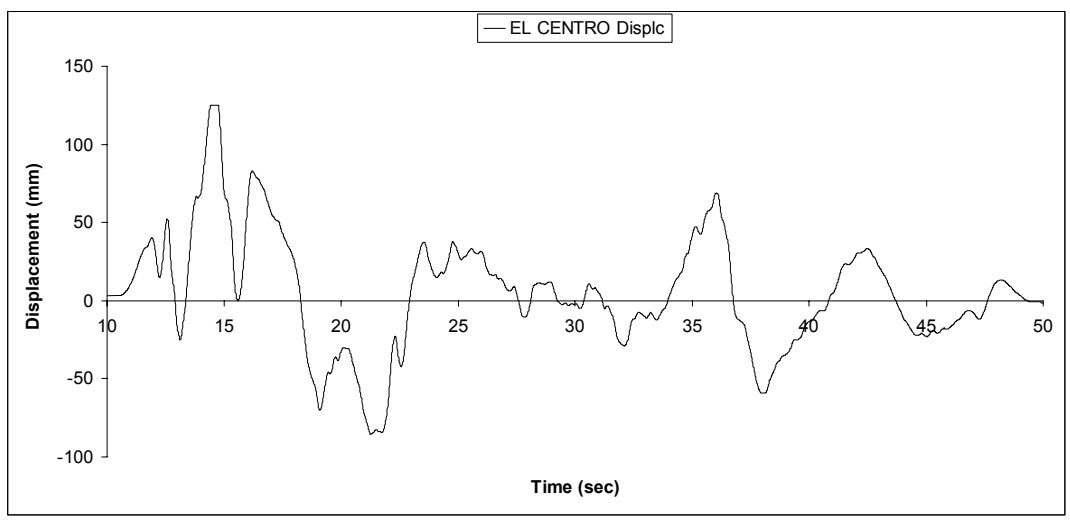

Figure 3: $\quad$ Input displacement signal, El Centro (1940) modified. 


\subsection{Test one}

For the first test, to establish the functionality of the frame, the El Centro earthquake displacement signal was applied to the frame with no additional loading on the system.

To collect force, displacement and acceleration data from the shake frame, a variety of devices were used. The MTS actuators are complete with load cells and Linear Variable Differential Transformers (LVDTs) that allow the measurement of the force and the displacement produced by them. In addition, a Resistive Potentiometer was connected to the frame to obtain displacement measurements.

Through means of the load cells, the MultiPurpose TestWare software indicated that the load differential between the actuators was in the range of 5 to $15 \mathrm{kN}$. The LVDTs indicated that the displacement errors relative to each other were minimal, and that the accuracy of each LVDT for the applied signal relative to the input signal was $\pm 5 \mathrm{~mm}$. Upon further investigation, it was observed that the severity of the errors and differentials depended on the characteristics of the input signal; i.e. when using a sine wave signal with low frequency and short stroke, the errors in displacement and the load differentials were small compared to an input signal with the same frequency and stroke but with a ramp shape, or the same sine wave with a higher frequency.

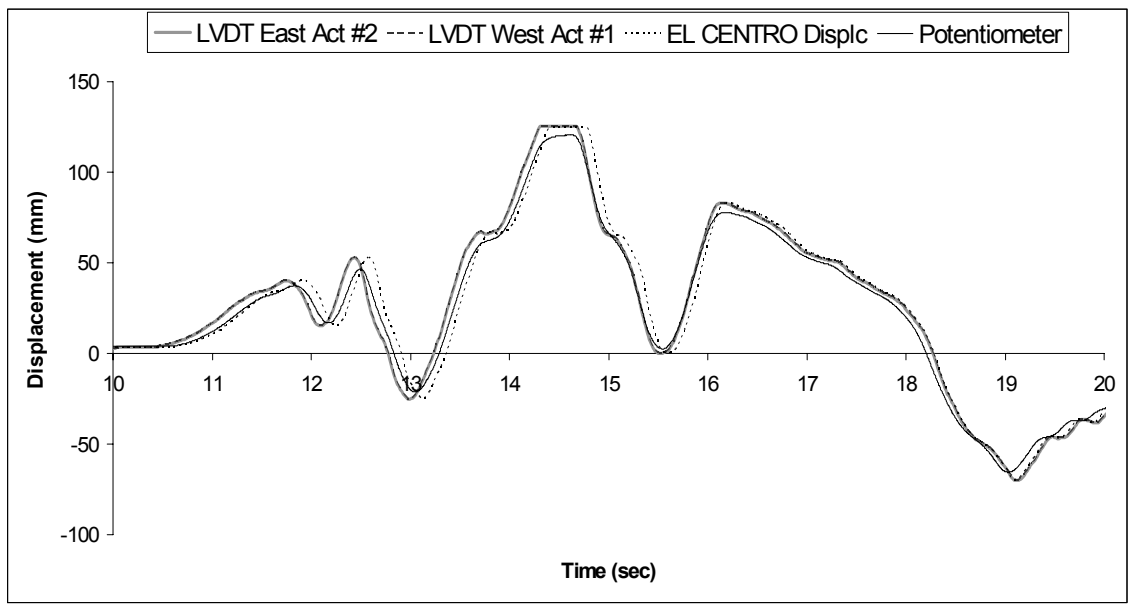

Figure 4: Displacement signals from LVTDs, potentiometers and El Centro input.

According to the LVDT for Actuator 1, the maximum displacement, registered during the simulated earthquake, was $125.24 \mathrm{~mm}$ and the maximum displacement measured by the LVDT in Actuator 2 was $125.34 \mathrm{~mm}$. The difference between these two is $0.10 \mathrm{~mm}$. From this, it can be inferred that the actuators work simultaneously (synchronized) and with a minimal displacement differential (Figure 4). 
A comparison of the plotted data from the LVDTs and the El Centro earthquake input signal shows that the shake frame is displacing exactly as it is programmed to (Figure 4). However, in the Station Manager of the MTS software there are some features (Meters) that allow the user to monitor the system signal; and, by setting them to monitor the Running Max/Min Displacement Error it was observed that the maximum error registered during the program was $5 \mathrm{~mm}$. Furthermore, by analysing the plotted data from a Resistive Potentiometer connected to the frame (Figure 4), it was noticed that the maximum displacement reached during the running of the program was $120 \mathrm{~mm}$, while the system was programmed to have a maximum displacement of $125 \mathrm{~mm}$; a difference of $5 \mathrm{~mm}$. This number is consistent with the MTS Meters output data.

Figure 5 shows a comparison between the wall's acceleration, the derived acceleration and the location of the maximum displacement. Using KISTLER KBeam Accelerometers to collect acceleration data from the shake frame, and applying filters $(0.2 \mathrm{~Hz}$ High Pass and $15 \mathrm{~Hz}$ Low Pass) to reduce noise and unwanted vibrations, it was noticed that the acceleration signal from the shake frame and the one derived from the input displacement data were almost the same. There are two points (at 4 and $4.31 \mathrm{~s}$ ) where the acceleration increases significantly as a result of the adjustments to the displacement signal.

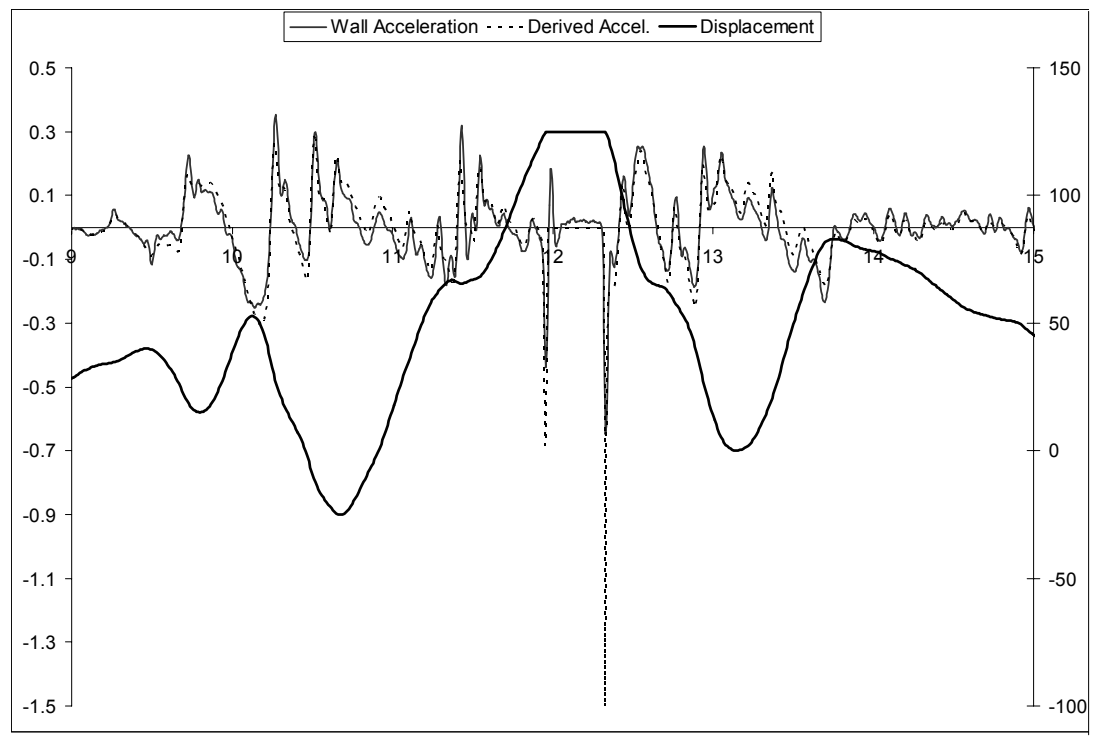

Figure 5: The wall's acceleration, derived acceleration and displacement over the first $6 \mathrm{~s}$. 


\subsection{Second test}

Finally, to verify the functionality of the shake frame when additional mass is applied, two concrete masonry walls were built in place, on the side beams of the shake frame. The walls were $1 \mathrm{~m}$ long x $1.6 \mathrm{~m}$ high and $200 \mathrm{~mm}$ thick, with a total mass of approximately $500 \mathrm{~kg}$ (both walls). They were attached to the frame using two threaded rods grouted only in the first course. No other reinforcement was used in the walls. They were tested after 28 days.

Using a videogrammetry system, Tait et al. [3], to measure displacement by means of video cameras and fixed visual targets, displacement data from the shake frame was obtained. A comparison of the input displacement signal, the potentiometer (unloaded frame), and the videogrammetry (loaded frame) shows a minimal difference in relation to each other. As observed in the first test, there is a $5 \mathrm{~mm}$ maximum error compared with the input data, but the loaded and unloaded signals are practically the same (Figure 6 and 7) indicating satisfactory performance of the system.

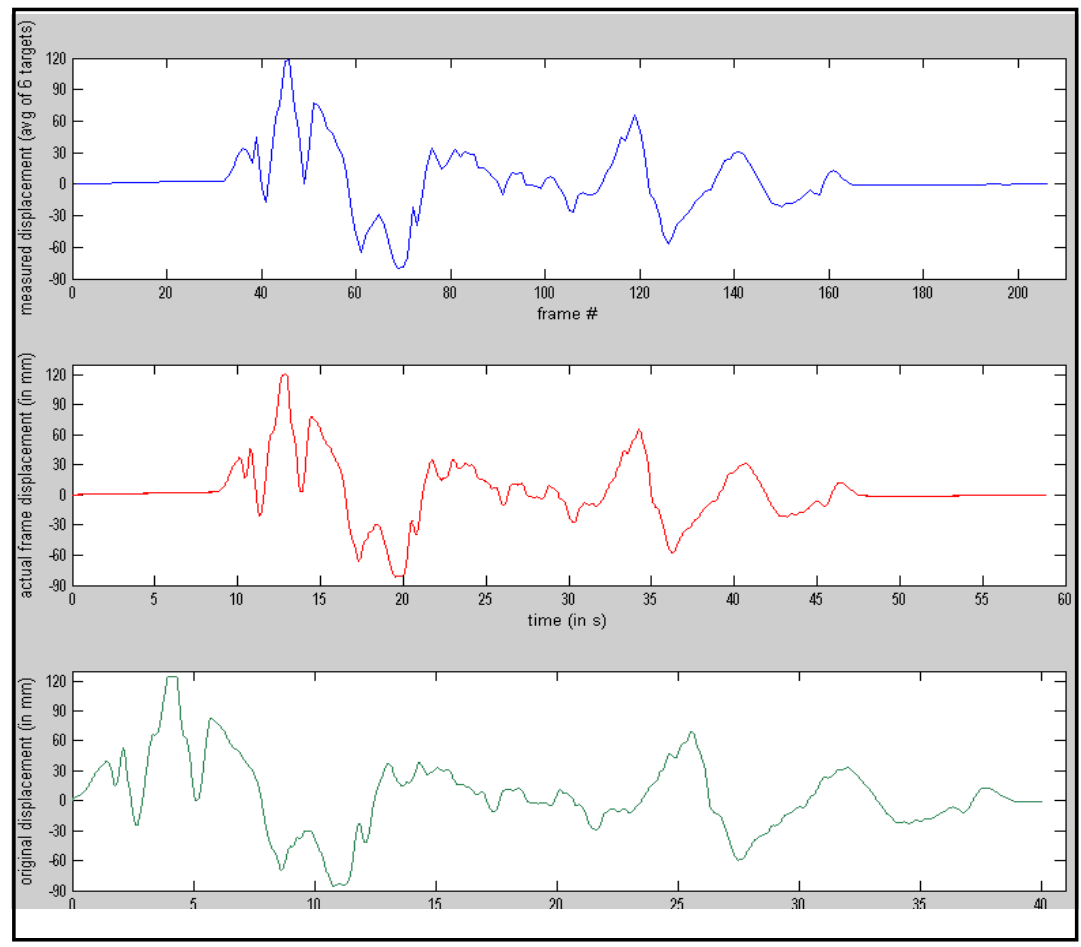

Figure 6: Videogrammetry, potentiometer and original input signals (Tait et al. [3]). 


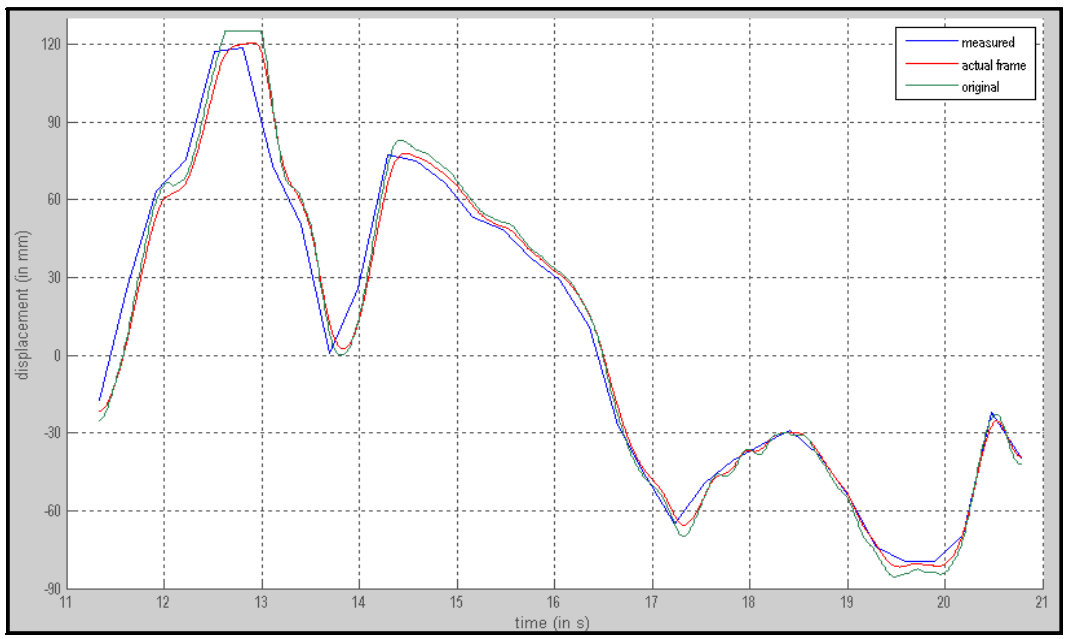

Figure 7: The original input, potentiometer and videogrammetry signals over the first $10 \mathrm{~s}$ (Tait et al. [3]).

(a)

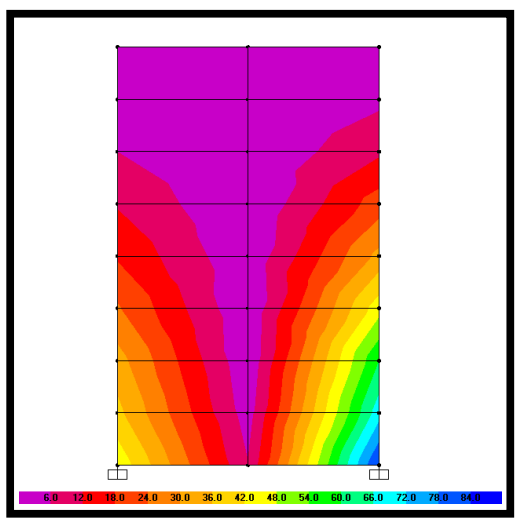

(b)

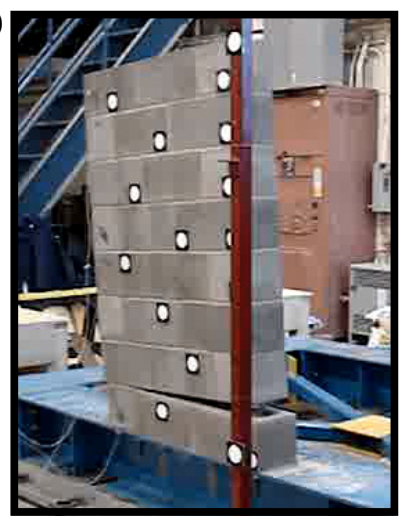

Figure 8: (a) Distribution of stresses inside the wall (SAP2000); (b) wall failure.

A Finite Element model of the masonry walls was created using SAP2000. The walls were simulated by means of Shell Elements; 16 elements of $0.50 \mathrm{x}$ $0.20 \mathrm{~m}$ and $200 \mathrm{~mm}$ thick. Applying the acceleration signal from the unloaded shake frame on the SAP model, and establishing a comparison of the acceleration data obtained from the walls, at $0.10,0.90$ and $1.50 \mathrm{~m} \mathrm{high}$, and the acceleration from the SAP model at similar heights, indicated that the model was an accurate representation of the walls. 
Figure 8(a) shows the inside tensile stress distribution in one of the walls. High stresses are detected at the lower part of the model, the closest to the bottom of the wall the higher the stresses. This corresponds with the failure mode of the walls, bond failure at the bed joints (Figure 8(b)).

\section{Conclusions}

The maximum error registered by the different sensors used in the experiments was $5 \mathrm{~mm}$. This represents $4 \%$ of the maximum input displacement $(125 \mathrm{~mm})$.

The readings obtained by the LVDTs in the actuators indicated that the actuators worked synchronized and according to the specifications.

Although the displacement signal was modified due to the limits of the actuators, the acceleration derived from that signal varied compared very well to the original El Centro earthquake acceleration signal. Nevertheless, the shake frame accurately reproduced the input signal in both of the experiments (unloaded and loaded conditions).

The finite element model, developed for further masonry dynamic tests, was proven to reasonably predict the behaviour of masonry elements when subjected to dynamic loading.

\section{References}

[1] M.D. Hagel, S.L. Lissel, and T.G. Brown, Design of a seismic simulation frame for testing of masonry structures, Proceedings of the 13th International Brick and Block Masonry Conference Amsterdam, July 4-7, 2004.

[2] S. Ammanagi, V. Poornima, A. Sera, and R. Sunder, Development of a digitally-controlled 3-axis earthquake shake table, Current Science, Jan 2005.

[3] M. Tait, I. Couloigner, M. J. Guzman, and S. L. Lissel, Vision base deformation monitoring of a masonry wall under simulated earthquake conditions, EUSIPCO 2007. 